Tohoku J. Exp. Med., 1994, 174, 155-165

\title{
Human Prostate Acid Phosphatase is Carrier Protein for ABH Blood Group Antigens of Semen
}

\author{
Minoru Nakazato \\ Department of Legal Medicine, Faculty of Medicine, \\ University of the Ryukyus, Okinawa 903-01
}

\begin{abstract}
Nakazato, M. Human Prostate Acid Phosphatase is Carrier Protein for ABH Blood Group Antigens of Semen. Tohoku J. Exp. Med., 1994, 174 (2), 155165 - Prostate acid phosphatase (PAcP) was characterized as one of carrier proteins for $\mathrm{ABH}$ blood group antigens in semen. The diluted semen was sensitized with anti-PAcP. The resulting immunocomplex was subjected to SDS-PAGE after being washed with saline. SDS-PAGE patterns of the immunocomplex consisted of four bands. After electroblotting from gel to nitrocellulose filter, immunostaining using anti-PAcP or monoclonal anti-blood group antibodies was performed. The result showed that the protein of $50 \mathrm{kD}$ was the subunit of PAcP and the band of $94 \mathrm{kD}$ was identified with blood group antigens respectively. Other two bands were rabbit IgG against PAcP and its fragment. When semen was treated with the chemicals such as papain, SDS, 2-mercaptoethanol and dithiothreitol, the $\mathrm{ABH}$ of antigen which was captured by anti-PAcP were considerably reduced. The reduction of $\mathrm{ABH}$ activity by these treatments indicated that $\mathrm{ABH}$ antigens were located on $\mathrm{PAcP}$ in semen which was inactivated by the treatment. Therefore, $\mathrm{PAcP}$ was one of proteins carrying ABH epitopes in semen in addition to $\alpha_{2}$-seminoglycoprotein. $—$ blood group; immunocomplex; prostate acid phosphatase; carrier protein
\end{abstract}

$\mathrm{ABH}$ blood group antigens are distributed in not only blood but various tissues and organs of human and animal bodies. The $\mathrm{ABH}$ antigens in human body fluid have also been reported (Oshiro et al. 1981, 1984; Nakazato et al.1993). It is known that $\mathrm{ABH}$ epitopes in semen and saliva are located in some proteins, carrier proteins (Sagisaka et al. 1989; Tan and Yoshioka 1992). For example, $\mathrm{ABH}$ antigens in semen are distributed in $\alpha_{2}$-seminoglycoprotein (Tsuda et al. 1988).

Therefore, when antibody against $\alpha_{2}$-seminoglycoprotein was used as capturing antibody, $\mathrm{ABH}$ blood group of only semen from mixed stains with semen and vaginal fluid could be detected ( $\mathrm{Iki}$ et al. 1988). The presence of proteins carrying $\mathrm{ABH}$ epitopes in saliva was shown, however, the full characterization of the proteins was not yet performed (Nagae et al.1993). Amylase was not a carrier protein in saliva, and prostate acid phosphatase was not confirmed to be a carrier

Received April 7, 1994; revision accepted for publication September 6, 1994. 
protein in semen because of its non-specific adsorption to the ELISA plates (Sagisaka et al. 1990). In the previous study we demonstrated, by the absorption and elution method, that Wakogel B-5 coated with rabbit anti-semen could selectively capture $\mathrm{ABH}$ antigens of semen in the stains mixed up with other body fluid (Oshiro et al. 1992). This paper describes whether or not human prostate acid phosphatase is carrier protein.

\section{Materials and Methods}

\section{Specimens}

Samples of secretory semen were collected from volunteers. Semen samples were kept at $-50^{\circ} \mathrm{C}$ until use.

\section{Antisera, monoclonal antibodies (MCA) and human PAcP}

Human anti-A and -B, and mouse MCA anti-A and -B were purchased from Ortho (Raritan, NJ, USA), and mouse MCA anti-H from Chembiomed (Edmonton, Canada). Rabbit anti-human PAcP was obtained from ICN Immuno Biologicals (Lisie, IL, USA). Human PAcP was obtained from Chemicon (Temecula, CA, USA).

\section{Immunostaining of protein carrying $A B H$ antigen on nitrocellulose filter (NCF)}

Three round shaped NCFs of $8 \mathrm{~mm}$ diameter (Pro Bind 45; Pharmacia, Uppsala, Sweden) were immersed in $250 \mu$ l of $1: 5$ diluted anti-PAcP overnight, respectively, then washed with phosphate buffer saline $(\mathrm{pH} 7.2)$ containing $0.05 \%$ Tween 20 (PBS-T) three times and blocked with $1 \%$ bovine serum albumin (Sigma, V, St Louis, MO, USA) for $1 \mathrm{hr}$. Each NCF was incubated with the same amount of $1: 1,000$ diluted semen at $37^{\circ} \mathrm{C}$ for $3 \mathrm{hr}$.

After washing, $50 \mu 1$ mouse MCA anti-A, anti-B (agglutination titer; $\times 256$ ) was added. Nonreactive MCAs were removed and followed by washing with PBS-T three times. Then $50 \mu 1$ of $1: 500$ diluted horseradish peroxidase (HRP) conjugated goat anti mouse IgM (Tago, Burlingame, CA, USA) was added, after incubation at $37^{\circ} \mathrm{C}$ for $1 \mathrm{hr}$. The NCF was washed, and $100 \mu \mathrm{l}$ of the substrate solution (PBS buffer containing $0.05 \%$ diaminobenzidine and $0.01 \%$ hydrogen peroxide) was added. In this system, anti-PAcP as capturing antibody and MCAs against blood group antigen as detecting antibodies were used.

As reverse system, $250 \mu 1$ of $1: 10$ diluted MCAs to blood group antigen were used as capturing antibodies and the same amount of $1: 5$ diluted anti-PAcP was used as detecting antibody. In this test, protien A gold kit (E-Y Laboratories, San Mateo, CA, USA) was used for the detection of binding anti-PAcP.

\section{SDS-PAGE of immunocomplex formed from semen and anti-PAcP}

Two hundred microliter of A and B type semen (1:16) was sensitized with the same volume of anti-PAcP $(1: 4)$ overnight at $4^{\circ} \mathrm{C}$. Resulting immunocom- 
plex was collected by centrifugation at $8,000 \mathrm{xg}$ for $10 \mathrm{~min}$, washed with chilled saline and this procedure was repeated. The pellet was dissolved in $30 \mu \mathrm{l}$ of phosphate buffer (30 mM, pH 7.0) containing 1\% sodium dodesyl sulfate (SDS), 5 $\mathrm{mM}$ dithiothreitol (DTT) and $0.01 \%$ bromophenol blue (BPB), and then incubated at $37^{\circ} \mathrm{C}$ for $2 \mathrm{hr}$. The solution was immediately absorbed to a sample application piece made of Paratex on Excel Gel SDS (Pharmacia). SDS-polyacrylamide electrophoresis (SDS-PAGE) was performed by a Multiphor II Electrophoresis System (Pharmacia) for $80 \mathrm{~min}$ as described by the manufacturer. Thirty $\mu 1$ of human PAcP and molecular weight marker (HMW kit for SDS-PAGE; Pharmacia) were electrophoresed on the same gel. The gel was stained with $0.1 \%$ Coomassie Blue R-250 for $10 \mathrm{~min}$.

\section{Electroblotting}

Electroblotting of proteins from a gel to NCF was carried out by a NovaBlot system (Pharmacia) at $180 \mathrm{~mA}$ for $60 \mathrm{~min}$. NCF blots were blocked with $1 \%$ BSA at room temperature for $60 \mathrm{~min}$ and sensitized with $10 \mathrm{ml}$ of MCA anti-A, -B and $-\mathrm{H}(1: 100)$ for $60 \mathrm{~min}$. After washing with PBS-T, $10 \mathrm{ml}$ of HRP conjugated goat anti-mouse IgM $(1: 1,000)$ was added and incubated for $60 \mathrm{~min}$ at $37^{\circ} \mathrm{C}$. Then, $10 \mathrm{ml}$ of the substrate was added. For detection of PAcP, NCF blots were sensitized with $2 \mathrm{ml}$ of anti-PAcP $(1: 10)$ at room temperature for $3 \mathrm{hr}$, then protein A gold kit was used.

For identification of rabbit IgG against PAcP, NCF blots were sensitized with $10 \mathrm{ml}$ of $\mathrm{HRP}$ conjugated goat anti-rabbit IgG $(1: 500)$ at room temperature for $3 \mathrm{hr}$, then, $10 \mathrm{ml}$ of the substrate solution was added.

\section{The activity of $P A c P$ in the immunocomplex}

To examine the activity of PAcP in the immunocomplex, the substrates such as SM reagent (Ishizu Pharmaceutical, $\alpha$-naphthylphosphoric acid and diazonium o-dianisidine), p-nitrophenyl phosphate and phenolphthalein diphosphate were dropped on filter paper stained with the phosphate buffer solution of immunocomplex, respectively.

\section{ELISA}

Microtiter plates (Sumitomo bakelite, Tokyo) were coated with $50 \mu \mathrm{l}$ of anti$\mathrm{PAcP}(1: 5)$ at $4^{\circ} \mathrm{C}$ overnight. After washing with PBS-T 3 times, the plates were blocked with $100 \mu \mathrm{l}$ of $1 \% \mathrm{BSA}$ at room temperature for $2 \mathrm{hr}$. After washing, 50 $\mu$ l of 1:10 diluted A. Se semen was added, followed by incubation at room temperature for $3 \mathrm{hr}$. Fifty $\mu \mathrm{l}$ of MCA anti-A (1:50) was added and incubated at room temperature for $2 \mathrm{hr}$. Then $50 \mu \mathrm{l}$ of $1: 500$ diluted HRP conjugated goat anti-mouse IgM was added and incubated at room temperature for $2 \mathrm{hr}$. Fifty $\mu \mathrm{l}$ of the substrate solution was added. After incubation at room temperature for 1 $\mathrm{hr}$, absorbance at $492 \mathrm{~nm}$ was measured with a reader (MPR-A4i; Toyo Soda, 
Tokyo). A. Se semen was treated with following chemicals; 1) one-fourth volume of $10 \%$ papain (Merck, F.U. VII, Darmstadt, Germany), 2) 20\% SDS, 3) $10 \%$ 2-mercaptoethanol (2-ME), 4) 10\% DTT at room temperature for $30 \mathrm{~min}$, respectively. These treated semen samples were subjected to ELISA as described above. Non-treated semen was used as control.

To check the effect of these chemicals to the coated anti-PAcP, $50 \mu \mathrm{l}$ of each chemical was added to the plate. After washing, $50 \mu \mathrm{l}$ of $1: 500$ diluted HRP conjugated goat anti-rabbit IgG was added and incubated at room temperature for $2 \mathrm{hr}$, then, $50 \mu \mathrm{l}$ of the substrate solution was added. After incubation at room temperature for $1 \mathrm{hr}$, absorbance at $492 \mathrm{~nm}$ was measured.

\section{RESULTS}

Anti-PAcP used in the present study showed a single precipitation line with the diluted semen $(1: 10)$ by the double diffusion plate test (Fig. 1).

Results of the capturing activity of anti-PAcP adsorbed into NCF are shown in Fig. 2. Proteins captured with anti-PAcP showed the specific activity to MCA anti-A or -B respectively and the blood groups detected were consistent with those of semen. In the reverse system, proteins captured with MCA anti-A or -B were sensitized with anti-PAcP and were subsequently stained with protein A gold kit. As shown in Fig. 3, PAcP was selectively captured with the corresponding MCA anti-A or -B to the blood groups of semen. These results suggest that PAcP is one of proteins carrying $\mathrm{ABH}$ epitopes.

Immunocomplex formed from semen and anti-PAcP was collected by centrifugation and washed with chilled saline. The reaction of the immunocomplex and substrates such as SM, p-nitrophenyl phosphate and phenolphthalein

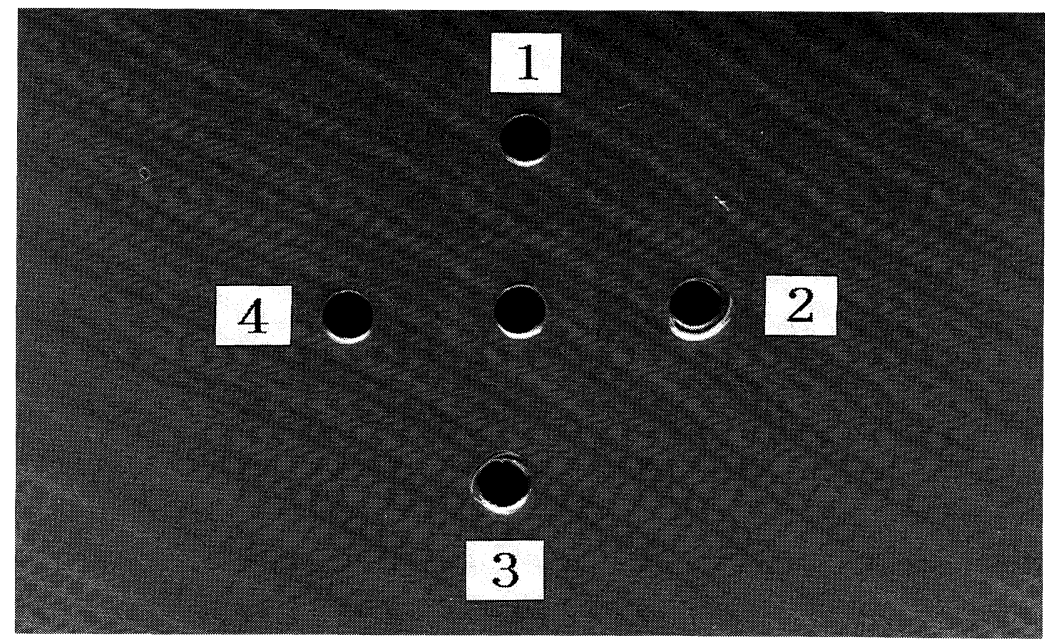

Fig. 1. Double diffusion plate test (Ouchterlony test) of anti-PAcP against semen. A type semen (1), B type semen (2), $O$ type semen (3) and AB type semen (4). 


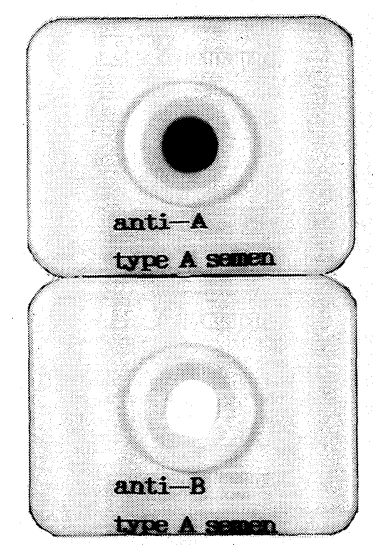

Blood

Type
A

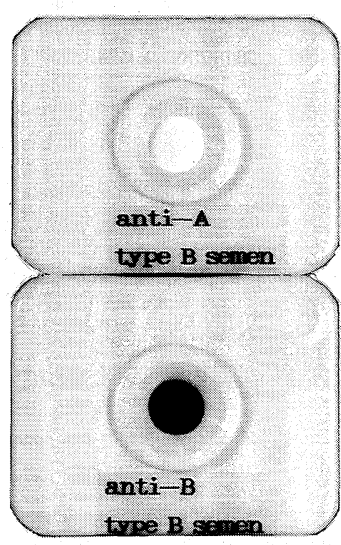

B

Fig. 2. Immunostaining by MCA anti-A and $-\mathrm{B}$ of the proteins in semen captured with anti-PAcP using MCA anti-A and -B.

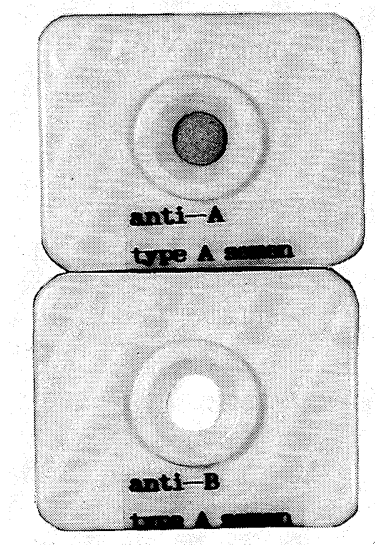

\section{Blood}

Type
A

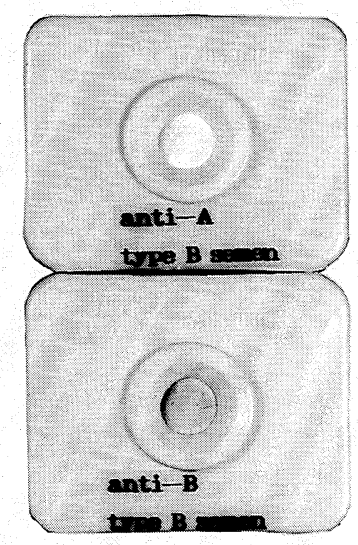

B

Fig. 3. Immunostaining by anti-PAcP of the proteins in semen captured with MCA anti-A and -B using anti-PAcP.

diphosphate showed that PAcP in the immunocomplex retained the enzymic activity (Fig.4).

SDS-PAGE patterns of PAcP, semen and immunocomplex are shown in Fig. 5. PAcP observed as $50 \mathrm{kD}$ band infers the subunit of $110 \mathrm{kD}$ dimeric protein. Semen specimens shared 8-10 bands in the range of $15-150 \mathrm{kD}$ and SDS-PAGE patterns of blood group $\mathrm{A}$ and $\mathrm{B}$ semen were similar. Of these bands, the corresponding proteins to $94 \mathrm{kD}, 67 \mathrm{kD}, 50 \mathrm{kD}$ (PAcP), $35 \mathrm{kD}$ and $18 \mathrm{kD}$ bands are 
1

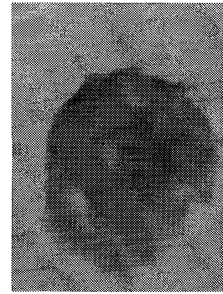

2

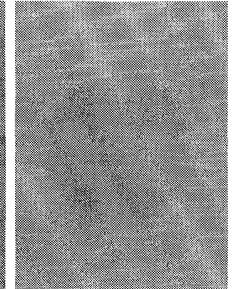

3

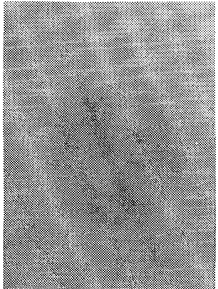

Fig. 4. The enzymic activity of PAcP in the immunocomplex. SM reagent (1), P-nitrophenyl phosphate (2) and phenolphthalein diphosphate (3).

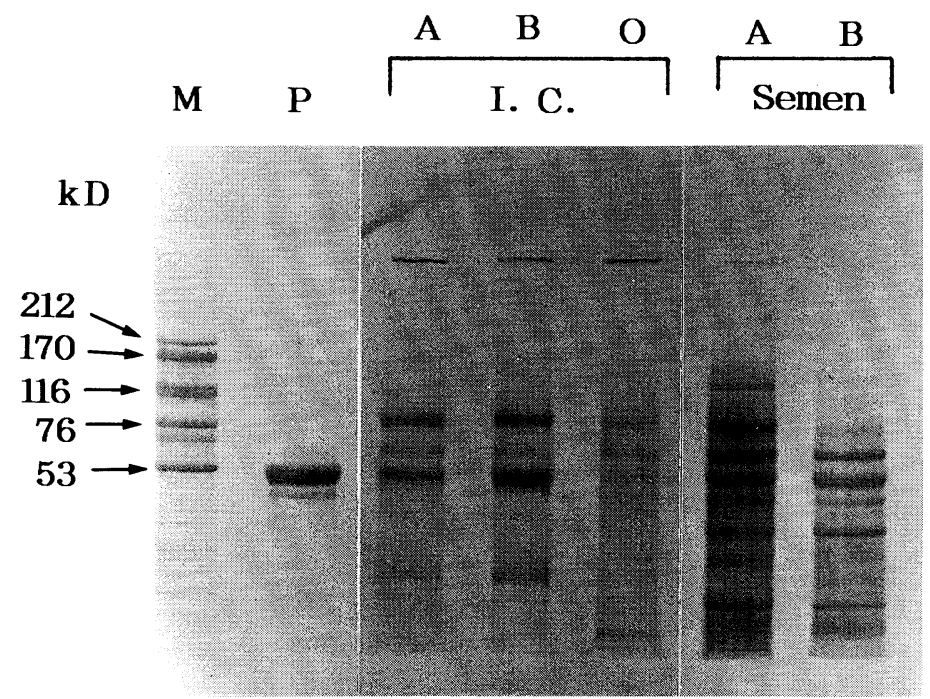

Fig. 5. SDS-PAGE patterns of PAcP, semen and immunocomplex formed from anti-PAcP and semen. M, molecular weight marker; P, PAcP; I.C., Immunocomplex.

major ones. The patterns of immunocomplex formed from anti-PAcP and blood group $\mathrm{A}, \mathrm{B}$ and $\mathrm{H}$ semen consisted of 4 bands, and $\mathrm{PAcP}$ of $50 \mathrm{kD}$ and protein of $94 \mathrm{kD}$ were major bands. After electroblotting to NCF from gel of SDS-PAGE, immunostaining using MCA anti-A, $-\mathrm{B}$ and $-\mathrm{H}$ was performed. Fig. 6 shows the results of immunostaining using MCAs as detecting antibodies. The band of 94 $\mathrm{kD}$ was selectively detected with the corresponding MCA anti-A, $-\mathrm{B}$ or $-\mathrm{H}$ to the blood groups of semen. The band of $50 \mathrm{kD}$ was positively stained using antiPAcP as shown in Fig. 7. Therefore, the band of $94 \mathrm{kD}$ is blood group substance and the band of $50 \mathrm{kD}$ is PAcP. This may imply the dissociation of PAcP and blood group antigens from immunocomplex during the SDS-PAGE. Another two minor bands were not stained with MCA anti-blood groups and anti-PAcP but with anti-rabbit IgG (Fig. 8). 


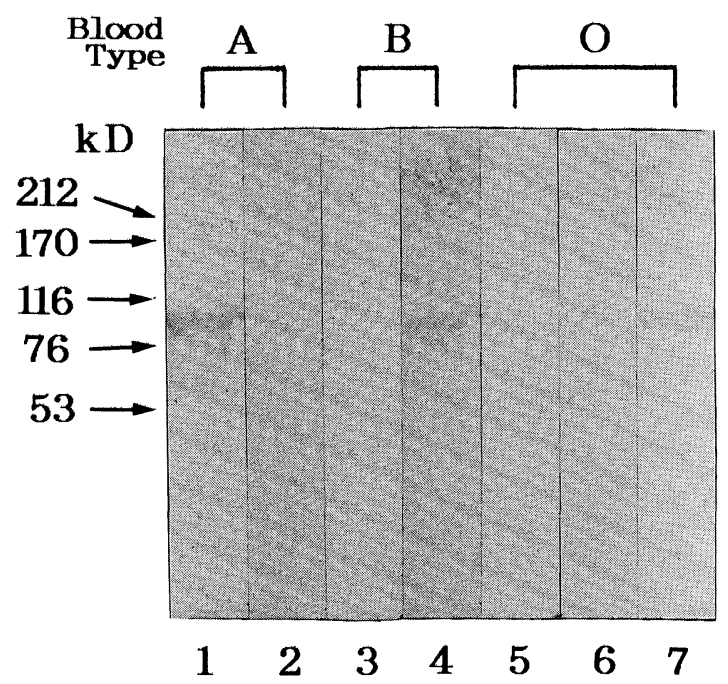

Fig. 6. Immunostaining of the proteins in semen transfered from gel after SDSPAGE of immunocomplex from anti-PAcP and semen using MCA anti-A, -B and $-\mathrm{H}$. MCA anti-A (1,3 and 5), anti-B (2, 4 and 6$)$ and anti-H (7).

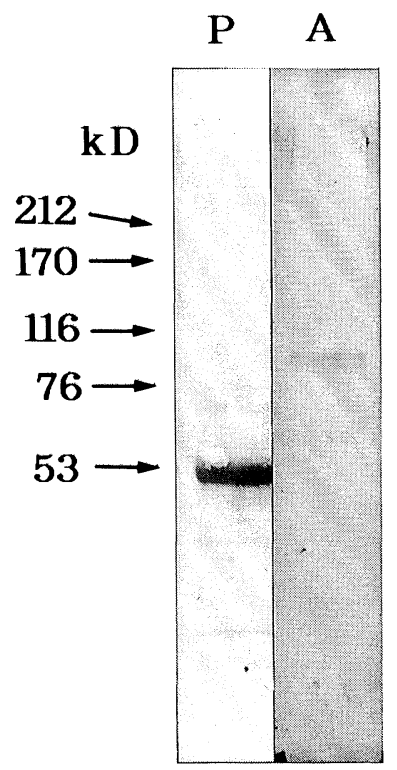

Fig. 7. Immunostaining of the proteins in semen transfered from gel after SDS$\mathrm{PAGE}$ of immunocomplex from anti-PAcP and semen. Anti-PAcP $(\mathrm{P})$ and MCA anti-A (A). 


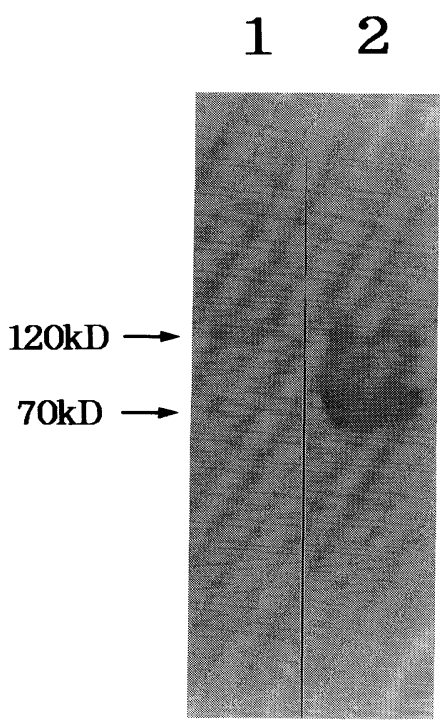

Fig. 8. Immunostaining of the proteins transfered from gel after SDS-PAGE of immunocomplex from anti-PAcP and semen. 1, immunocomplex; 2, rabbit anti-human PAcP.

TABLE 1. Comparison of the captured $A B H$ blood group activity of semen treated by various chemicals (Double antibody sandwich-ELISA)

\begin{tabular}{cccrrr}
\hline & \multicolumn{5}{c}{ Treatment } \\
\cline { 2 - 6 } & Control & Papain & SDS & 2-ME & DTT \\
\hline Relative & 100 & 48 & 10 & 48 & 51 \\
activity (\%) & & \pm 11 & \pm 2 & \pm 11 & \pm 12 \\
\hline
\end{tabular}

Relative activity expressed the persentage of control experiments.

Mean \pm S.D. $(n=8)$

TABLE 2. The effect of various chemicals to anti-PAcP coated on ELISA plate

\begin{tabular}{ccccrr}
\hline & \multicolumn{5}{c}{ Treatment } \\
\cline { 2 - 6 } & Control & Papain & SDS & 2-ME & DTT \\
\hline Relative & 100 & 80 & 86 & 87 & 77 \\
activity (\%) & & \pm 3 & \pm 9 & \pm 1 & \pm 6 \\
\hline
\end{tabular}

Relative activity expressed the persentage of control experiments.

Mean \pm S.D. $(n=5)$ 
A. Se semen $(1: 10)$ treated with chemicals such as papain, SDS, 2-ME and DTT was added to microtiter plates coated with anti-PAcP $(1: 5)$. Then, blood group $\mathrm{A}$ activity was examined by MCA anti-A and HRP conjugated anti-mouse IgM.

The relative activities of the captured $\mathrm{ABH}$ blood group of semen treated by various chemicals are shown in Table 1 . SDS treatment markedly reduced the $\mathrm{ABH}$ activity of the semen, and papain, 2-ME and DTT considerably.

The coated anti-PAcP was slightly inactivated with these chemicals (Table 2). Nevertheless, the effect of chemicals to semen was greater than that to anti-PAcP.

\section{Discussion}

In a previous study, we demonstrated that chemical adsorbent, Wakogel B-5, adsorbed anti-seminal plasma antibody could capture the $\mathrm{ABH}$ antigens from the trace seminal stain sufficiently enough to show blood type of semen (Oshiro et al. 1992). By this method, $\mathrm{ABH}$ blood groups of semen in the stains mixed up with vaginal secretion or blood were successfully determined.

Sagisaka et al.(1990) demonstrated the presence of protein carrying ABH antigens in saliva using double antibody sandwich-ELISA, however, PAcP in semen was not confirmed to be carrier protein because of its non-specific adsorption to the ELISA plates.

In the present study, some experiments have been performed to confirm whether or not PAcP is carrier protein. The anti-PAcP adsorbed to NCF could capture the protein carrying the $\mathrm{ABH}$ epitopes from the $1: 1,000$ diluted semen. Consequently, the $\mathrm{ABH}$ antigens of semen could be detected correctly using MCAs to blood group antigens. In the reverse system, the protein captured with MCAs to blood group antigens was positively stained using anti-PAcP and protein A gold kit. These results suggest that $\mathrm{PAcP}$ is one of the proteins carrying $\mathrm{ABH}$ epitopes in semen. Tamaki and Kishida (1990) demonstrated that MCA anti- $\alpha_{2}$ seminoglycoprotein (SGP) showed potent capturing activity to $\mathrm{ABH}$ epitopes in semen. Therefore, SGP is one of proteins carrying ABH epitopes in semen. PAcP is proposed as another carrier protein for $\mathrm{ABH}$ blood group antigens. SDS-PAGE patterns of the immunocomplex formed from anti-PAcP and semen consisted of 4 bands. Of these bands, after electroblotting the protein of $94 \mathrm{kD}$ could be stained by MCA blood group anti-A, -B or -H and HRP conjugated anti-mouse IgM indicating the presense of blood group antigens. On the other hand, PAcP was detected from the band of $50 \mathrm{kD}$ separately as the subunit of dimeric protein.

These results suggest that the proteins captured with anti-PAcP have dissociated from the immunocomplex to each components during SDS-PAGE. However, there is possibility of non-specific co-precipitation with anti-PAcP and blood group antigens. Thus the double antibody sandwich ELISA was performed after 
treatments of semen specimen with various chemicals as described by Sagisaka et al. (1990). When semen was treated with papain, SDS, 2-ME and DTT, the ABH antigen activities of semen captured by anti-PAcP were considerably reduced.

The reduction of $\mathrm{ABH}$ activity by treatment with various chemicals indicated that $\mathrm{ABH}$ antigens were located on proteins in semen which were inactivated by the treatments.

These results showed that $\mathrm{ABH}$ antigens were located on $\mathrm{PAcP}$ in semen. Therefore, PAcP was characterized as one of the carrier proteins in semen in addition to SGP.

Wakogel B-5 on which anti-PAcP was adsorbed could collect $\mathrm{ABH}$ blood group antigens of semen from samples of 10 raped cases and the results of absorption elution test were in agreement with their blood group of the suspects determined by red cell agglutination test, respectively (data not shown). Therefore, $\mathrm{ABH}$ blood grouping of semen in the stains mixed up with vaginal secretion or blood must be successfully performed by the present method in forensic practice.

\section{References}

1) Iki, H., Minamitake, H., Tsuda, R. \& Hara, M. (1988) Detection of ABO blood group of seminal stains mixed with vaginal secretion or blood by a method using NCF coated with anti $\alpha_{2}$-SGP serum. $J p n$. J. Legal Med., 42, 504-508. (in Japanese with English abstract)

2) Nagae, M., Aoki, Y., Nata, M. \& Sagisaka, K. (1993) Diversity of saliva proteins carrying $\mathrm{ABH}$ epitopes. Acta Crim. Jpn., 59, 89-92.

3) Nakazato, M., Iha, M. \& Omine, M. (1993) ABO blood grouping by using chemical adsorbents 3. Determination of respectitive ABO blood group from mixed stains of saliva and blood. Rep. Natl. Res. Inst. Police Sci., 46, 1-5. (in Japanese with English abstract)

4) Oshiro, S., Nakazato, M. \& Kikuzato, A. (1981) ABO blood grouping by using chemical adsorbents 1 . On the saliva, urine and sweat. Rep. Natl. Res. Inst. Police Sci., 34, 197-204. (in Japanese with English abstract)

5) Oshiro, S., Nakazato, M., Iha, M., Kikuzato, A. \& Omine, M. (1984) ABO blood grouping by using chemical absorbents 2 . On the semen, vaginal secretion, feces and contents of stomach. Rep. Natl. Res. Inst. Police Sci., 37, 1-7. (in Japanese with English abstract)

6) Oshiro, S., Nakazato, M. \& Iha, M. (1992) Detection of ABH antigens of semen in the stains mixed up with other body fluid by using chemical adsorbent. Rep. Natl. Res. Inst. Police Sci., 45, 59-63. (in Japanese with English abstract)

7) Sagisaka, K., Fletcher, S.M., Katura, S. \& Yokoi, T. (1989) Specific capture of ABH blood group antigens of the red cell or body fluids by double antibody sandwichELISA. Tohoku J. Exp. Med., 158, 211-219.

8) Sagisaka, K., Aoki, Y., Yokoi, T. \& Nata, M. (1990) On the proteins carrying ABH epitopes in saliva and semen. Acta Crim. Jpn., 56, 189-193.

9) Tamaki, Y. \& Kishida, T. (1990) Production and characterization of monoclonal antibody to $\mathrm{ABH}$ carrying alpha 2-seminoglycoprotein for $\mathrm{ABO}$-grouping of semen by enzyme-linked immunosorbent assay (ELISA). Adv. Forens. Haemogenetics, 3, 182184.

10) Tan, Q. \& Yoshioka, N. (1992) ABO blood group activity of low molecular weight 
glycoprotein in semen. Res. Pract. Forens. Med., 35, 35-39. (in Japanese with English abstract)

11) Tsuda, R., Ito, Y. \& Hara, M. (1988) Immunochemical studies of a glycoprotein $\left(\alpha_{2}\right.$-Seminoglycoprotein; $\alpha_{2}$-SGP) in seminal plasma-Forensic immunological studies of body fluids and secretions, Report 33. Jpn. J. Legal Med., 42, 28-37. (in Japanese with English abstract) 